\title{
DEL ATRASO A LA CONVERGENCIA. LA RED DE CARRETERAS EN ESPAÑA, 1900-2010
}

\author{
M. ${ }^{a}$ Inmaculada López Ortiz* \\ Joaquín Melgarejo Moreno** \\ Universidad de Alicante
}

\section{RESUMEN}

La necesidad de dar respuesta al freno que suponía la deficitaria red de transporte terrestre para el crecimiento de la economía se convirtió en un objetivo básico de la política inversora del Estado durante el siglo xx. Un primer esfuerzo constructor se produjo en el primer tercio del siglo, dando inicio a la etapa contemporánea del transporte por carretera en España. Tras el parón de la postguerra civil, un nuevo impulso tuvo lugar a partir de 1960 y hasta la crisis de mediados de los setenta, multiplicándose las inversiones destinadas a este fin. Durante la transición asistimos a una brusca caída de las inversiones que llevó aparejado un estancamiento de la longitud de la red y a la transferencia de una parte de las carreteras a las nacientes Comunidades Autónomas. El país realizó, desde mediados de los ochenta y ayudado por los fondos europeos, un esfuerzo considerable, pasando de país atrasado a converger con Europa en equipamiento de grandes infraestructuras de transporte.

Palabras clave: Red de Carreteras, Infraestructura Viaria, Transporte, Comunicaciones

\section{ABSTRACT}

The need to address the constraint on the growth of the Spanish economy caused by the deficient road transport network became a primary objective of the State's investment policy during the whole of the 20th century. An initial effort to build the network was made in the first thirty years of the century, marking the start of the contemporary era of road transport in Spain. This development was interrupted by the civil war, then, a new boost in road construction took place between 1960 until the crisis of the mid 1970s, a period during which investments in road infrastructure were multiplied. During the

\footnotetext{
* iortiz@ua.es

**jmelgar@ua.es
} 
Transition period there was a sharp fall in investments, no efforts were made to extend the length of the network and the competences for part of the roads were transferred to the newly-formed Autonomous Regions. From the mid-1980s and with the help of European funds, Spain made a considerable effort to modernise its network. It is no longer underdeveloped and has converged with the rest of Europe in terms of its largescale transport infrastructure facilities.

Keywords: Road Network, Road Infrastructure, Transport, Communication

\section{INTRODUCCIÓN}

La infraestructura se define como aquella parte del capital global de las economías, que debido a su carácter, principalmente público, no es suministrada normalmente por el mercado, y por tanto está sujeta a las decisiones políticas. Ese carácter de bien público explica que la intervención del Estado bien como regulador o directamente como inversor sea habitual; $y$, aunque es cierto que en ocasiones la intervención pública puede ser sustituida por el capital o el trabajo privado, lo importante desde la óptica del desarrollo económico es el coste que entraña esa sustitución. Por otra parte, la infraestructura, en tanto que acervo físico y material que permite el desarrollo de la actividad económica y social, está considerada como un factor determinante o limitador del crecimiento económico. Existen muchas referencias acerca del papel de las infraestructuras en el crecimiento económico. Así, desde el Mercantilismo se viene afirmando que las «actividades del príncipe» son fuente de desarrollo y bienestar; e incluso los economistas clásicos, como Adam Smith, que repudiaban la dependencia excesiva de las actividades públicas y ensalzaban los beneficios de la acción individual, no dejaban de reconocer que los caminos, los puertos y las vías fluviales eran requisitos importantes de la riqueza de las naciones. Más recientemente, la idea de considerar las infraestructuras como capital social fijo ha cobrado especial relevancia ${ }^{1}$. Básicamente, se reconocen dos vías a través de las cuales las infraestructuras pueden condicionar la evolución de una economía. De un lado, porque su construcción y utilización pueden generar una demanda importante de productos de otros sectores, con el consiguiente impacto sobre el nivel de producción de estos, y teniendo en cuenta, además, los efectos multiplicadores asociados. De otro, porque los servicios proporcionados por las infraestructuras pueden introducir cambios en la estructura de costes de las empresas, al propiciar aumentos de productividad. Así, un aumento de la dotación de infraestructuras en un área concreta tiene, en principio, consecuencias positivas inmediatas

1. Hirschman (1958), Tinbergen (1962), Ashauer (1989, 1993). Una visión panóramica de la bibliografía sobre infraestructuras y crecimiento económico puede verse en Biehl $(1986,1988)$, Argimón et al. (1994), Draper y Herce (1994), De La Fuente (1996) y Álvarez et al. (2003). 
sobre los costes de las empresas por dos vías. Primero, porque conlleva la reducción del precio de algunos inputs; y, segundo, porque provoca descensos en el precio del output y del resto de los inputs, gracias a la reducción general de los costes de transporte y de distribución de los bienes.

Se puede afirmar, por tanto, que las inversiones públicas en infraestructuras son un importante instrumento de política económica, desencadenante de relevantes efectos económicos, que en momentos de crisis, además, pueden actuar como elemento de estabilización anticíclica. Podría decirse más bien que hasta fechas recientes, en vigencia del modelo keynesiano, han sido concebidas como instrumentos de política procíclica, al ser utilizadas como elementos de ajuste presupuestario. Son numerosos y diferentes los efectos que puede producir una misma inversión sobre la actividad económica, ya que estos dependerán de las circunstancias y agentes que concurran. Así, por ejemplo, puede hablarse de efectos sobre la demanda agregada o sobre la oferta agregada, macroeconómicos o microeconómicos, a corto o largo plazo, a escala nacional o regional, globales o sectoriales, cualitativos o cuantitativos, entre otros. En términos generales, puede afirmarse que los efectos de una mejora de las infraestructuras repercuten en el crecimiento de la productividad general de la economía de un lugar, aumentan la actividad económica e incrementan el potencial de recaptación de ingresos por parte de la administración pública² ${ }^{2}$.

En España las infraestructuras se han percibido, casi sin discusión, como solución definitiva a los problemas del país, y como tal han formado parte del discurso político de las diferentes épocas. Debe tenerse en cuenta, además, que las obras públicas constituyen un excelente medio de legitimación gracias a su visibilidad, lo que las convierte en testimonio directo de los logros de un gobierno o un régimen. También debe considerarse que la política de infraestructuras es un recurso fácilmente adaptable a las exigencias coyunturales del presupuesto, en contraste con otras políticas que inciden en el crecimiento y precisan de una acción continuada. El caso español, por último, constituye un ejemplo de utilización de la política de infraestructuras al servicio de la jerarquización territorial y de la ordenación del poder.

El estudio del establecimiento y la modernización de la red de carreteras llevados a cabo en España en el transcurso del siglo xx y hasta la actualidad es precisamente el objeto de este trabajo.

2. Un análisis sobre el impacto económico de las infraestructuras de transporte utilizando funciones Coob-Douglas y con ecuaciones que relacionan la productividad con retardos de la inversión en infraestructuras puede verse en Nombela (2005). En el trabajo se demuestra la importancia de las inversiones públicas en infraestructuras de transporte en España en el período 1955-2002, al evidenciarse la existencia de elasticidades positivas y significativas sobre la producción y la productividad del factor trabajo. 


\section{ANTECEDENTES: ORIGEN Y CONSOLIDACIÓN DEL SISTEMA RADIAL}

La red de caminos de la España de los Austrias tuvo su origen en la red de calzadas romanas de los siglos II y IV d. C. Ésta presentaba unas características básicas de conexión en malla formando una estructura descentralizada, en la que predominaban los itinerarios de este a oeste que discurrían por los valles de los grandes ríos peninsulares, mientras otros iban de norte a sur y algunos en diagonal que conectaban con los anteriores ${ }^{3}$. Tras la Guerra de Sucesión, la nueva dinastía borbónica decidió adoptar el modelo francés como referencia para la ordenación territorial y el ejercicio del poder. Las comunicaciones terrestres se convirtieron en elemento fundamental para asentar la posición política y económica de Madrid como capital del reino (Segura, 2000:15). Así y con la finalidad de poder llevar a cabo su política centralizadora, los Borbones emprendieron con cargo a la Corona la construcción de la red de carreteras modernas de España $^{4}$ (Uriol, 1977). Entretanto, los caminos no radiales siguieron financiados por aquellos que obtenían beneficios directos de su utilización, y sobre todo por los municipios. En 1761 se puso en marcha un plan general de carreteras que se inspiraba en las recomendaciones de Bernardo Ward, quien proponía seis carreteras radiales básicas que coincidían con los caminos radiales de posta del Reglamento de 1720 (Uriol, 1990); insistiendo Ward en la necesidad de ejecutar con cargo a la Hacienda la construcción de estos caminos y en la participación de los usuarios en los costes de mantenimiento mediante peajes. Los legisladores borbónicos intentaron con esta red satisfacer objetivos administrativos (correo e información), militares y de orden público (abastecimiento de Madrid); pero sin embargo dejaron de lado cuestiones de índole puramente económica como la baratura y la regularidad de los acarreos (Gómez Mendoza, 2001)5. Con todo, puede afirmarse que, a principios del siglo XIX, se había hecho realidad la integración vial del reino. La Guía General de Correos, Postas y Caminos de 1830 definía como caminos generales o de primer orden los construidos por el

3. Madrazo (1984), Uriol (1985), Álvarez Junco (2001).

4. La reforma del servicio de Correos, que desde el siglo xvi había estado concesionado a intereses privados, se plasmó en el Reglamento General para la Dirección y Gobierno de los Oficios de Correo mayor y Postas de España de 1720. En él se establecía la relación de las «Carreteras de Postas», que configuraba una red radial centralizada en Madrid, complementada con un camino paralelo al Mediterráneo (entre Barcelona y Alicante), otro paralelo a la frontera portuguesa (entre Benavente y Sevilla), y la conexión entre Burgos y Medina del Campo por Valladolid.

5. Gómez Mendoza (2001:348) ha destacado el papel que en el establecimiento de esta red desempeñó una cuestión de enorme importancia, como fue el abastecimiento de la capital, cuyas crecientes necesidades de abastecimiento se vieron agravadas por la escasa dimensión de las actividades productivas que se desarrollaban allí, lo que hizo que, en general, el transporte a la capital fuese de grandes dimensiones y asimétrico, ya que no existía prácticamente retorno de mercancías desde Madrid. A ello se sumaron a las necesidades planteadas por el transporte militar y la distribución de monopolios públicos como la sal y el tabaco. 
gobierno, o que tenía intención de construir, que partiendo de Madrid llegaban a las orillas del mar o a alguna de las fronteras ${ }^{6}$. Al final del reinado de Fernando VII había construidos en España unos 5.000 kilómetros de carreteras. Cantidad exigua si se la compara con los 30.000 con los que contaba Francia en esos mismos años, lo que da buena cuenta del retraso y la escasez de carreteras que tenía el país (Alzola, 1979:337). Este problema se agravaba si se consideraba que la comunicación interior, fuera de las carreteras reales, era prácticamente inexistente (Ford, 1974:60). Con Isabel II se inició la regularización de la financiación de las obras públicas en general y de las carreteras en particular, asignándose para tal fin dotaciones en los presupuestos generales del Estado 7 . De 1836 es la Ley de expropiación forzosa que regula los cuatro trámites clásicos de declaración de utilidad pública, necesidad de ocupación, justiprecio y pago; mientras que la Ley de 1851 estableció la clasificación de carreteras en España en generales, transversales, provinciales y locales ${ }^{8}$. En 1855 la red de carreteras generales y transversales se estimaba en 8.324 kilómetros y en 1896 se contaba con 32.512 kilómetros; es decir, en 40 años se había cuadruplicado la red viaria y prácticamente se había terminado el plan de carreteras de los años sesenta. Analizando las cifras de inversión bruta elaboradas por Herranz (2004:45), pueden identificarse varios periodos de mayor esfuerzo constructivo por parte del Estado, destacando la última fase del reinado de Isabel II, en la que se terminó casi en su totalidad la red de carreteras de «primer orden», y el período de 1880 a 1890, que coincidirá con el máximo apogeo del fenómeno de las llamadas «carreteras parlamentarias», en alusión a la presión política ejercida por los diputados para conseguir carreteras para sus distritos electorales, que fueron introducidas en los planes generales por la maquinaria caciquil. En definitiva, a partir de 1855 la red de carreteras se convirtió en uno de los protagonistas indiscutibles de la inversión en infraestructuras junto con los ferrocarriles. Sin embargo, ello no fue óbice para que, a finales del siglo XIX, persistiesen algunos problemas tales como el exceso de vías incluidas en el Plan de 1877 y el profundo retraso en el desarrollo de las redes provinciales y de los caminos vecinales, salvo en el País Vasco y Navarra. De nuevo, la comparación con Francia muestra la magnitud

6. La Guía incluye sólo diez en esta categoría: Madrid-Francia por Burgos, Madrid-Francia por Zaragoza, Barcelona y la Junquera; Madrid-Valencia; Madrid-Barcelona por Almansa y Valencia; Madrid-Málaga por Jaén, Granada y Loja; Madrid-Cádiz por Córdoba y Écija; Madrid-Portugal por Badajoz; Madrid-La Coruña por Medina del Campo y Benavente; MadridGijón por Valladolid y León; y Madrid-Santander por Valladolid y Burgos (Uriol, 1992:17).

7. Ello no obstó para que durante algún tiempo coexistieran estas asignaciones con los fondos propios impuestos sobre la sal, portazgos y peajes.

8. La financiación de las generales y transversales correspondía en parte al Estado y en parte a las provincias, si bien la conservación correspondía al Estado en su totalidad. Las provinciales eran financiadas por las provincias, aunque podían obtener subvenciones del Estado; y los caminos locales eran competencia municipal. 
del atraso español en este punto: en 1896 había en España 6.832 kilómetros de carreteras provinciales y 19.300 de caminos vecinales; mientras que en el país vecino las cifras ascendían a 38.000 kilómetros de carreteras provinciales y 613.000 kilómetros de caminos provinciales.

\section{LA MODERNIZACIÓN DE LA RED Y SU VINCULACIÓN CON LA EXPANSIÓN DEL AUTOMÓVIL. DEL ATRASO AL TRIUNFO DE LA AUTOMOCIÓN SOBRE EL FERROCARRIL}

En los inicios del siglo xx y sobre todo en el período comprendido entre las dos guerras mundiales, la intervención pública adquirió un mayor protagonismo en la resolución de los problemas económicos, y el aumento de las obras públicas fue un reflejo de ello. Las obras públicas se convirtieron en un instrumento en manos de los gobernantes para afrontar la crisis económica en el período de entreguerras y el territorio se constituyó en el destinatario de fuertes inversiones, respondiendo así a los requerimientos de una sociedad cada vez más motorizada y tecnificada.

A comienzos del siglo xx, el ferrocarril de ancho normal en España estaba prácticamente terminado, con más de 10.789 kilómetros en servicio. La ventaja de este medio respecto al transporte por carretera en cuanto a velocidad, coste, seguridad y confort, inclinaba claramente a su favor la competencia en la captación de tráficos. La práctica totalidad de los viajeros usaban el ferrocarril y la mayor parte del tráfico de mercancías discurría sobre raíles. Los coches de caballos y las diligencias sólo subsistían complementando los servicios al ferrocarril ${ }^{9}$. Esta situación de hegemonía ferroviaria se modificó de forma radical con la aparición del automóvil y su paulatina implantación, dando comienzo a una importante revolución tecnológica: la mecanización del transporte por carretera ${ }^{10}$. Así, en los primeros años del siglo xx, se recuperó la vitalidad de este medio para el transporte de viajeros, que se había perdido en favor del tren. Por su parte, la revitalización del transporte de mercancías por carretera se inició en los años previos a la Primera Guerra Mundial, aunque fue durante ésta

9. Ya fuese aportando viajeros a las estaciones o recogiéndolos de ellas; o bien manteniendo sus servicios para distancias cortas y en aquellos itinerarios en los que la mayor extensión de carreteras y caminos, respecto al trazado ferroviario, daba ventaja a este medio, al evitar la rotura de carga de carro a ferrocarril o de ferrocarril a carro, y permitir el transporte directo puerta a puerta.

10. El automóvil, alentado por el movimiento vanguardista, se convirtió en uno de los iconos centrales de la modernidad; $y$, correlativamente, las carreteras se articularon como infraestructura real y simbólica de los nuevos tiempos (Rodríguez Lázaro, 2004:294). Comienza a hablarse en esos momentos de la «carretera del porvenir» (Rodríguez Lázaro, 2004:36). 
cuando se puso en evidencia las ventajas de los nuevos vehículos: automóviles, autobuses y camiones ${ }^{11}$.

La aparición y expansión de la automoción exigieron una mejora de las carreteras, de manera que el desarrollo de la moderna red viaria estuvo íntimamente ligado a la incorporación de los automóviles a la vida de los españoles, lo que propició que se pasara definitivamente de los viejos caminos a las modernas carreteras. Al final de la Gran Guerra el automóvil ya presentaba un ascenso imparable y fue el momento en que se dotó a las carreteras de nuevos firmes, de más calidad que la sencilla piedra partida ${ }^{12}$. Entre 1897 y 1925 se construyeron 23.207 kilómetros de carreteras en España. La legislación básica que lo posibilitó fue la Ley de carreteras de 1887 y el pliego de condiciones generales para la construcción y la formulación de proyectos de 1903. El Plan General de Carreteras de 1911 sustituyó al de 1877 y, en 1914, el Plan Gasset estableció el programa de construcción de carreteras que estaría vigente hasta 1939. Asimismo, entre 1911 y 1925, se crearon más de 10.000 kilómetros de caminos vecinales ${ }^{13}$.

Un importante hito fue la creación por Real Decreto de 9 de febrero de 1926 del Circuito Nacional de Firmes Especiales (CNFE). Puede decirse que con él se inicia la época contemporánea del transporte por carretera en España. Los objetivos básicos del CNFE fueron: el fomento del turismo y atender al tráfico creciente de automóviles. Precisamente, el organismo fue planificado para favorecer el turismo en automóvil, ligándolo al Patronato Nacional del Turismo (Rodríguez Lázaro, 2004). En el Preámbulo del RD de creación del CNFE quedaron recogidos sus objetivos, extensión de la mejora, la organización adoptada y los recursos financieros a emplear. Así, se afirmaba:

El alto interés nacional de fomentar el turismo, enalteciendo las bellezas naturales y la riqueza artística de España, proporcionando para ello los medios fáciles

11. Se estima que en 1925 el número de automóviles en circulación era de unos 85.000. Los vehículos más frecuentes en las calles y carreteras eran los de $15 \mathrm{CV}$ entre los automóviles y los de 2,5 Tm entre los camiones (Aguilar, 1925:153)

12. Se sustituyeron los firmes de piedra machacada (técnica macadán), adecuados para la tracción animal, por otros nuevos en los que se evitaba la desagregación de los materiales, como los adoquinados y los asfaltados. La primera solución al problema fue el alquitranado a partir de de 1906, procedimiento que estuvo muy vinculado con el desarrollo de la industria del petróleo, también íntimamente relacionada con la del automóvil; ya que comenzaron a aparecer en el mercado grandes cantidades de betunes asfálticos, un subproducto con precios muy competitivos, que mejoraba sustancialmente las propiedades de los aglomerados que se usaban en la pavimentación (Grupo ESM, 1995:30).

13. La Ley de 30 de julio de 1904 sobre promoción de caminos vecinales preveía a tal fin una subvención estatal de un $25 \%$, quedando las diputaciones encargadas de financiar el resto. Los terrenos los pondrían los ayuntamientos y las prestaciones personales los vecinos. El RD de 20 de marzo de 1925, que aprobó el estatuto provincial de vías y obras, encargaba a las diputaciones la construcción de los nuevos caminos vecinales y la conservación de los existentes. 
y gratos de simultanear la seguridad de la circulación, ante una esmerada conservación de las carreteras, con la grata impresión que suponen abandonar la lucha secular con los baches y con el polvo, enemigos poderosos de la circulación de automóviles, y al mismo tiempo la imperiosa necesidad de cambiar el sistema técnico de la construcción de firmes (...) obligan a preparar una organización especial que facilite la realización de la mejora, de este cambio radical del sistema, que si no permite abordar la rápida transformación de toda la red de carreteras españolas, sea suficiente lograr la reforma y conservación de las comunicaciones principales, las que constituyen el enlace de las poblaciones de mayor importancia y los circuitos de gran valor histórico y artístico (...) Para lograr este fin se segregaran de la red de carreteras generales los itinerarios principales, y agrupados en circuitos parciales, se formará en su conjunto el Circuito Nacional de Firmes Especiales, para construcción y conservación se creará un Patronato administrativo y una Dirección técnica anexa, a cuyo organismo se dotará de recursos especiales y de facultades amplias para su funcionamiento (...) Es base fundamental de esta propuesta que no haya de imponerse al Estado ningún nuevo sacrificio, y tenga que contribuir tan sólo con los recursos que figuran en los Presupuestos Ordinarios ${ }^{14}$.

La organización adoptada fue la de un organismo nuevo con autonomía administrativa y financiera, con personalidad y medios propios. La aportación del Estado se financió con un Presupuesto Extraordinario, por un importe de 600 millones de pesetas, aprobado por RD de 9 de julio de 1926 (Rodríguez Saiz, 1979:454). También se sentaron las bases de los gravámenes a la circulación automóvil a través de la imposición indirecta sobre los carburantes ${ }^{15}$. Con el CNFE se proponían 15 circuitos cerrados, excepto en las fronteras y Cartagena. Entre 1926 y 1933 se construyeron 7.000 kilómetros de firmes y se repararon otros 6.619 kilómetros ${ }^{16}$. Pero el principal mérito del CNFE fue cambiar radicalmente el aspecto y la calidad de las carreteras españolas.

En 1931 se creó el Ministerio de Obras Públicas y todas las carreteras del Estado se integraron en la Dirección General de Caminos, incluidas las pertenecientes al Circuito de Firmes Especiales. Este organismo, no obstante, consolidó sus presupuestos durante el período republicano, e incluso se intentó que aumentara la extensión y el número de los itinerarios incluidos en él; si bien los gastos en conservación y reparación superaron a los de inversiones en construcción ${ }^{17}$.

14. Preámbulo RD 9/02/1926.

15. Por RD de 28 de junio de 1927 se estableció para la Península y Baleares el monopolio estatal del petróleo y sus derivados (CAMPSA), con el que se perseguían finalidades fiscales entre otras (Tortella, Ballestero y Díaz Fernández, 2003; Marín Quemada, 1979).

16. Información recogida en la Memoria del Plan de Modernización de la Red de Carreteras de España, 1950.

17. El RD de 23 de enero de 1934 autorizó la ampliación de la red a cargo del Circuito, suponiendo los nuevos itinerarios 1.161 kilómetros. El presupuesto del organismo fue de 29,5 millones en 
Según Uriol (1992:259), los presupuestos del CNFE son una buena demostración de que la política de carreteras republicana hizo suyo el objetivo del Circuito, consistente en mejorar la viabilidad de la red que soportaba el mayor tráfico de automóviles; por lo que puede afirmarse la continuidad de la política de carreteras de la etapa republicana respecto a las actuaciones que se habían llevado a cabo en etapas anteriores, lo que se materializó en la culminación del Plan Gasset de 1914 y en la consolidación del Circuito de Firmes Especiales. Los mayores logros de la etapa republicana radicaron en las obras de ampliación y mejora de los accesos a las grandes ciudades, especialmente Madrid. También debe mencionarse la aprobación en 1934 del Código de la Circulación, que ha estado vigente hasta 1992.

Tras el éxito del Circuito de Firmes Especiales, también se intentó la construcción de autopistas. La primera autorización para estudiar una carretera de pista directa de Madrid al Grao (Valencia) data de marzo de 1927, aunque fue por RD de 28 de julio de 1928 cuando se autorizó el otorgamiento de las concesiones para construir y explotar las autopistas Madrid-Valencia, Madrid-Irún y Oviedo-Gijón. En 1929 se autorizaron otros trayectos. El sistema de concesión español preveía la adjudicación mediante concursos públicos de libre licitación, estableciendo que las sociedades concesionarias debían ser españolas y que el plazo de la concesión sería de 99 años (García Ortega, 1979:48-53). Los trabajos, sin embargo, no pudieron comenzar ante la inviabilidad de introducir este tipo de carreteras especiales en un país que no había completado su red ordinaria y que tenía un nivel de tránsito todavía escaso, básicamente urbano, para soportar los costes. Entendidas como vías de lujo, las autopistas fueron asimismo desechadas durante los primeros años de la Segunda República y tampoco se acometió su construcción cuando, en 1935, ésta se planteó como posible estrategia contra el acuciante problema del paro obrero (Rodríguez Lázaro, 2004:294).

Como queda reflejado en el gráfico 1, desde mediados del siglo XIX asistimos a la creación de la moderna red viaria en España, correspondiendo los mayores esfuerzos al último tercio de dicha centuria y a las primeras décadas del xx, si bien sería en este último siglo cuando se desarrollaron las iniciativas tendentes a la modernización de los trazados. Como en tantas otras cosas, la Guerra Civil significó un brusco parón en este proceso.

1932; 30,2 en 1933; 30,2 en 1934; y 25 en 1935. Las obras ejecutadas consistieron, por una parte, en la extensión de firmes alternativos al macadam y, por otra, en actuaciones puntuales destinadas a la mejora y acondicionamiento de los itinerarios. En las obras de afirmado, se recurrió sobre todo a los riegos bituminosos superficiales y profundos, empleando en menor medida empedrados, hormigones asfálticos y hormigones en masa. Una característica singular del período fue la utilización de bordillos para el encintado del firme, práctica que se abandonó a partir de los años cuarenta. 
Gráfico 1. Evolución de la construcción de kilómetros de carreteras, 1830-1935

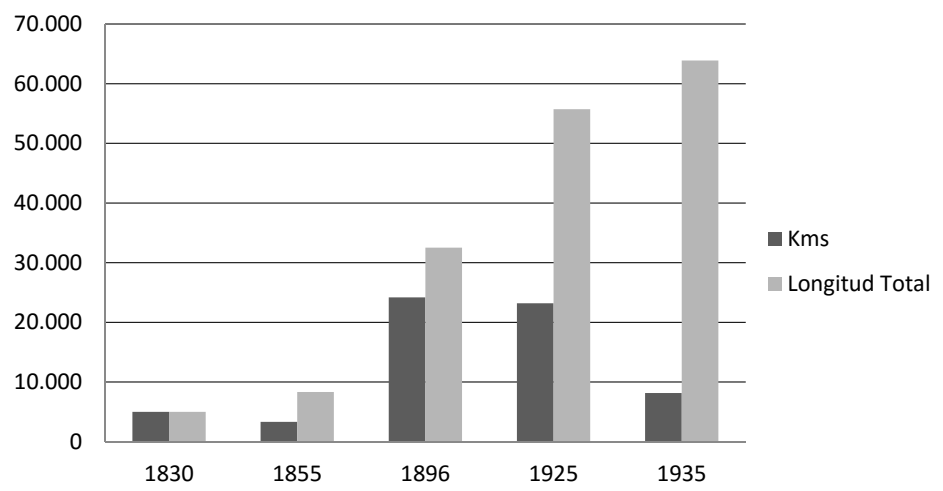

Fuente: Alzola (1979:337), Uriol (1992:60), Rodríguez Lázaro (2004:294), Memoria del Plan de Modernización de la Red de Carreteras de España (1950). Elaboración propia.

La dictadura franquista se encontró en 1939 con un país dañado por la guerra, cuya economía se hallaba profundamente desarticulada. Las infraestructuras estaban seriamente deterioradas, al haber sido uno de los objetivos prioritarios de las operaciones militares de ambos ejércitos. Lógicamente, las carreteras del país no quedaron al margen de esta negativa situación. La Revista de Obras Públicas, en su número especial de diciembre de 1940, cifró en 2.651 las obras de carreteras destruidas durante la guerra. Por su parte, de los 167.659 vehículos de cuatro ruedas que componían el parque móvil español en 1934, sólo quedaban, en 1940, 104.061, es decir, el 62\%. A esas pérdidas debía sumarse el envejecimiento de los vehículos y la total falta de renovación. En este adverso contexto, la política económica del primer franquismo contribuyó a agravar la situación y a demorar la recuperación ${ }^{18}$. En 1939 se aprobó el Plan General de Obras Públicas, elaborado bajo la dirección de Alfonso Peña Boeuf, ministro de Obras Públicas del primer gobierno franquista, entre 1938 y 1945. Este Plan se acompañó de una Instrucción de Carreteras, de 11 de agosto de 1939, que supuso la primera normativa técnica de construcción de carreteras adaptada a los requerimientos del automóvil ${ }^{19}$. Más tarde, por Ley de 18 de diciembre de 1946, se aprobó un Plan adicional de Caminos locales del Estado. El Plan de Peña Boeuf tenía como objetivo principal la reparación de los destrozos ocasionados por la guerra, reconstruyendo puentes

18. Al respecto de la situación económica de España durante el franquismo, véase Barciela, López, Melgarejo y Miranda, 2001.

19. En ella se estableció una clasificación de las carreteras según su longitud de ancho (nacionales, con 9 o más metros; comarcales, con 7,5; y locales, con 6), y se fijó un sistema de numeración para su designación (OM 11/8/1939). 
y reparando firmes. Sólo si había disponibilidad financiera, se contemplaba la construcción de nuevas carreteras y el acondicionamiento de las existentes. Sin embargo, la escasez de todo tipo de materiales imposibilitó que se lograra siquiera el primer objetivo, lo que llevó al ministro Peña a calificar de «casi milagro» el poder seguir circulando por carretera ${ }^{20}$. La negativa situación provocó una sustancial reducción del tráfico tanto de viajeros como de mercancías, de manera que, entre 1942 y 1945, los viajeros y mercancías transportados por carretera representaban tan sólo el 49\% y 74\% respectivamente de las cifras alcanzadas entre 1929-1930 (Uriol, 1992:269). Por su parte, el parque de vehículos en circulación no se recuperó hasta 1948 y el de turismos hasta 1950.

Por su parte, la cuestión de la construcción de autopistas perdió el protagonismo que había adquirido durante la década anterior al conflicto, aunque diversos particulares intentaron recuperar concesiones anteriores o solicitaron otras nuevas. La desastrosa situación económica del país y el considerable deterioro de la red de carreteras existente trasladaron la preocupación de políticos y técnicos hacia la reconstrucción, no contemplándose la construcción de autopistas en el Plan Peña. Ello no fue óbice para que en fecha tan temprana como 1942 entrara en explotación el primer tramo de autopista del país. Se trataba de la conexión entre la carretera nacional II y el aeropuerto de Barajas, con una longitud, eso sí muy exigua, de 1,88 kilómetros ${ }^{21}$.

El 18 de diciembre de 1950 se aprobó el Plan de Modernización de la Red de Carreteras Españolas. Se trataba, como en el caso del Circuito Nacional de Firmes Especiales, de un programa de mejora y acondicionamiento de la red, circunscrito inicialmente "a las carreteras de circulación más intensa», y al que seguirían, en etapas sucesivas, los trabajos correspondientes «a los itinerarios de circulación media y reducida». En realidad, únicamente llegaron a programarse las actuaciones relativas al primer grupo de carreteras, que comprendían, según la clasificación efectuada, seis itinerarios radiales, trece subradiales, diez periféricos, nueve complementarios y tres insulares. La red afectada, cuyo acondicionamiento se llevaría a cabo entre 1951 y 1955, totalizaba 10.909 kilómetros. El Plan de Modernización se debía financiar con el presupuesto ordinario, aunque se preveía la posible autorización para emitir deuda pública con la que poder

20. El propio ministro Peña Boeuf (1946:301) dejó claro los graves problemas de abastecimiento de materiales que tenía la España de la postguerra:

«Hubiera sido preciso disponer de un millón trescientas mil toneladas de asfalto, sólo para dar reparación completa de los 36.000 kilómetros que están en malas condiciones y regar superficialmente el resto; pero lejos de tener esa cantidad de asfalto, sólo pudo disponerse de 40.000 toneladas y 23.000 de alquitrán, con lo que la reparación ha sido tan precaria que sólo ha permitido salvar los grandes baches. Y como tampoco se disponía de cemento, nadie podrá negar que es casi un milagro poder circular todavía, relativamente bien, pero desde luego empeorando de día en día, con caracteres alarmantes».

21. «Las autopistas libres», ROP, 1978, 63-65. 
hacer frente a los previsibles incrementos de costes. Ante el incumplimiento de los objetivos en los plazos señalados, el Plan se prorrogó cinco años más (19551960), lo que se justificó por el «aumento incesante del tráfico, de la rapidez de la circulación y del tamaño y peso de los vehículos, así como por la inflación de costes $\rangle^{22}$. Con este Plan se intentaba dar respuesta a dos de los principales problemas que presentaba la deficitaria red: de un lado, sustituir los viejos firmes del Circuito Nacional de Carreteras para que pudieran soportar mayores cargas $\mathrm{y}$, de otro, ajustar las características geométricas del trazado para adaptarlas a las mayores velocidades. Se trataba de conseguir una red básica de más de 10.000 kilómetros de carreteras de 7 metros de anchura, capaces de soportar una circulación de entre 6.000 y 8.000 vehículos/día (García Ormaechea, 1957:294-295).

En cuanto a las autopistas, la Ley de 2 de febrero de 1956 se planteó como finalidad principal facilitar la construcción por empresarios de algunos tramos de carretera que, por su intensidad de tráfico, podían ser objeto de concesión con atractivo para el capital privado. Esta ley preveía la correspondiente concesión administrativa por un plazo de 75 años y la declaración de utilidad pública de las obras a los efectos de la expropiación de terrenos. A su amparo sólo se otorgó una concesión: el túnel de Guadarrama, que fue el primer tramo de peaje abierto en España, en $1963^{23}$.

Fue en la década de los sesenta cuando dio comienzo un período de modernización de la red de carreteras, a medida que se disparaba el número de vehículos que circulaba por ella. La correlación entre la modernización de la red viaria y la evolución del número de vehículos es manifiesta, como queda puede verse en el gráfico 2. Con la liberalización económica y la apertura al exterior que trajo consigo el Plan de Estabilización de 1959 la economía española entró en un ciclo de crecimiento intensivo. En este contexto expansivo, las insuficientes y atrasadas infraestructuras de transporte podían convertirse en un cuello de botella para la actividad económica; y ello podía resultar especialmente grave para las zonas que presentaban un mayor dinamismo, como era el caso de las áreas turísticas $^{24}$. Los objetivos perseguidos por la política de carreteras estuvieron

22. Preámbulo de la Ley de 22 de diciembre de 1955, que prorrogó el Plan de Modernización de Carreteras de 1950. Todavía en esas fechas, según el propio Plan, el 70\% de la longitud de las carreteras disponía sólo de firme de macadán, lo que da muestra de las importantes deficiencias que presentaba la red.

23. El primer túnel de Guadarrama fue construido por Canales y Puertos, y su concesión se asignó a Ibérica de Autopistas. En 1972 se horadó el segundo túnel de Guadarrama con medios mucho más modernos que los utilizados en 1963, siendo la concesionaria de las instalaciones Iberpistas.

24. Así, en 1962, el informe El desarrollo Económico de España del Banco Mundial recomendaba un esfuerzo en reparación y conservación de la red viaria existente, e indicaba que la única carretera importante de construcción necesaria en un futuro inmediato era la autopista de Levante, a lo largo de la costa Mediterránea, desde Gerona hasta Murcia, (Banco Mundial, 1962:312). 
en consonancia con la evolución del parque de vehículos de cuatro ruedas, que había pasado de 19.548 en 1951 a 450.119 en 1960, y había experimentado una sustancial renovación. A ello contribuyó de forma decisiva la creciente fabricación española de automóviles y camiones: SEAT (Zona Franca de Barcelona), FASA-Renault (Valladolid), Citroën (Vigo), Land-Rover-Santana (Linares-Jaén), ENASA (Pegaso), Barreiros (Madrid), Ebro (Barcelona), DKW (Vitoria) y Sava (Valladolid) ${ }^{25}$. Por primera vez desde la existencia del ferrocarril en España, los transportes interurbanos de viajeros y de mercancías por carretera superaron a los transportes ferroviarios. Con todo, fue en la década de los sesenta cuando dio comienzo un período de modernización de la red, a medida que se disparaba el número de vehículos que circulaba por ella. Entre 1960 y 1977 se produjo un auténtico boom automovilístico, pasándose de 546.753 vehículos de cuatro ruedas en 1961 a 7.120 .487 en 1977, afectando el crecimiento principalmente a los turismos (5.944.942 ${ }^{26}$. Desde comienzos de la década de los años sesenta la práctica totalidad de los vehículos que circulaban por el país era de fabricación nacional. Además de las empresas anteriormente citadas, se establecieron en la península Chrysler (Dodge-Simca, asociada inicialmente a Barreiros) y la Ford (Valencia); y España pasó en esos años de importadora a exportadora de automóviles.

Gráfico 2. Evolución de la red viaria y del número de automóviles en España, 1900-1985

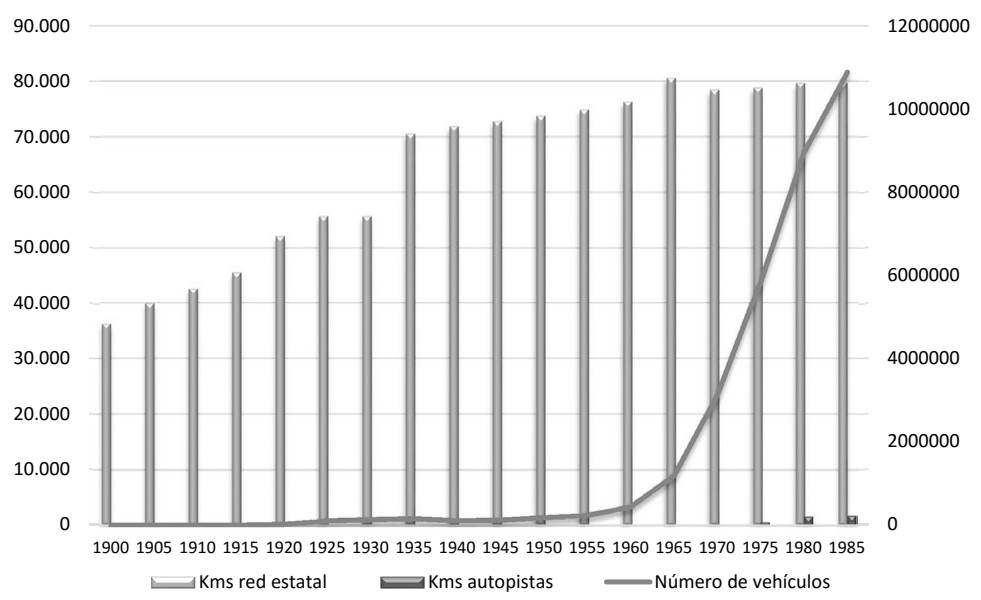

Fuente: Uriol (1992: 182-185). Elaboración propia.

25. Fernández de Sevilla (2011:143-159), Catalan (2011:259-316), San Román (1995:141-165; 2010).

26. Estadísticas de Transporte. Series cronológicas (1950-1977), Instituto de Estudios de Transportes y Comunicaciones (1979:81-83). 
Este aumento espectacular del parque móvil hizo necesario acometer en 1961 un nuevo Plan de Carreteras, que sustituyó al Plan Peña de 1939 y al Plan de Modernización de 1950. Este Plan se debía ejecutar en 16 años (1962-1977) y se estructuraba, para ello, en los correspondientes planes cuatrienales en coordinación con los Planes de Desarrollo, en consonancia con la política indicativa seguida en el país. La inversión prevista ascendía a 177.638,2 millones de pesetas. Por su parte, el Programa REDIA, Red de Itinerarios Asfálticos, se puso en marcha en 1967 y consistía básicamente en extender una capa de aglomerado asfáltico a lo largo de todo el itinerario, que comprendía 5.000 kilómetros. El presupuesto asignado fue de 20.000 millones de pesetas. Las carreteras que se incluyeron en el Programa fueron las seis radiales que partían de Madrid, a las que se le sumaron los itinerarios Alicante-Madrid, Alicante-La Junquera, Málaga-Cádiz y San Sebastián-Oviedo ${ }^{27}$. Aunque estaba previsto que los trabajos finalizarían en 1971, no fue así, produciéndose varios años de retraso en la ejecución de los mismos. Con todo, el Programa REDIA tuvo una favorable acogida por parte de los usuarios, ya que supuso una mejora sustancial de la $\operatorname{red}^{28}$. Finalmente, en 1978, el Programa de transformación de firmes de macadán propició que se alcanzara el objetivo que se había marcado, en 1926, el Circuito de Firmes Especiales, más de medio siglo antes: que todas las carreteras del Estado tuvieran firmes especiales.

En 1967 se redactó el Programa de Autopistas Nacionales Españolas (PANE), que preveía la construcción de 3.160 kilómetros de autopistas de peaje. Por su parte, la Ley 55/1960 sobre construcción, conservación y explotación de carreteras en régimen de concesión recogía los potenciales alicientes para la construcción de estas vías ${ }^{29}$. Al amparo de esta norma se construyeron el puente sobre la bahía de Cádiz, el túnel del Cadí en el Prepirineo catalán y el túnel de Tossas. Asimismo se programaron, en 1965, las dos primeras autopistas de peaje: Barcelona-La Junquera $(115,5 \mathrm{~km})$ y Mongat-Mataró $(17 \mathrm{~km})$, que fueron finalmente adjudicadas en 1972 (Llamazares, 1983:819). A finales de 1972

27. Las seis radiales eran la R-I (Madrid-Burgos-Irún), la R-II (Madrid-Barcelona), la R-III (Madrid-Valencia), la R-IV (Madrid-Cádiz), la R-V (Madrid-Badajoz) y la R-VI (Madrid-La Coruña).

28. El REDIA estableció un nuevo ancho de plataforma de 12 metros con arcenes de 2,5 metros a cada lado. Se trataba de una opción más ancha en general que las plataformas de las carreteras análogas europeas, lo que tenía sus ventajas al aumentar la seguridad, permitiendo aparcar fuera del carril con tráfico y utilizar los arcenes extraordinariamente; pero también tenía el inconveniente derivado de su mayor coste (Uriol, 1992:296).

29. Entre ellos, se contaban los peajes, la exclusividad de los servicios e instalaciones inherentes a la concesión, la calificación de preferente interés económico-social a efectos de aportaciones de capital extranjero y de importaciones de equipos, exenciones y bonificaciones fiscales, y exención del impuesto de la renta de las personas físicas en las suscripciones o adquisiciones de valores emitidos por las sociedades concesionarias (García Ortega, 1979:160). 
había en España 392 kilómetros de autopistas, de los cuales 272 se explotaban en régimen de peaje. El PANE se actualizó en el Avance del Plan Nacional de Autopistas de 1972, que preveía 6.430 kilómetros de autopistas y se financiaría exclusivamente con peaje (Bel, 1999:127). En 1975 sólo se habían adjudicado 2.042 kilómetros y, en 1981, estaban ejecutados 2.025 kilómetros de autopistas, de los que $1.710(80 \%)$ eran de peaje. De ellos el $75 \%$ se encontraban en el corredor mediterráneo (La Junquera-Alicante) y en el valle del Ebro (BilbaoZaragoza-El Vendrell) ${ }^{30}$. También se construyeron en esta etapa los tramos de la autopista del Noroeste entre Collado Villalba y Adanero, y el de la del Norte entre Burgos y Armiñón; la autopista entre Irún, en la frontera con Francia, y Bilbao, con la que se pretendía cubrir las necesidades de las grandes ciudades del Norte, enlazando toda la costa del País Vasco; y la autopista del Sur, entre Sevilla y Cádiz, que quedó abierta al tráfico en su totalidad en $1972^{31}$. Se trataba de los trayectos con más tránsito de mercancías y personas, por lo que en ellos se podría obtener mayores ingresos por peaje.

Los importantes aumentos sufridos por los costes de las obras y los de financiación de las empresas concesionarias de las autopistas, coincidiendo con un horizonte poco optimista en cuanto al tráfico potencial como consecuencia de los efectos de la crisis de los setenta, aconsejaron abandonar la construcción de nuevos itinerarios ${ }^{32}$.

30. Eran las autopistas del Mediterráneo, del Ebro y del Nordeste. En el caso de la autopista del Mediterráneo (AP-7), se trataba de su tramo más antiguo, que unía la frontera con Francia (La Junquera) con Alicante. Este fue construyéndose sucesivamente en la década de los setenta, inaugurándose el primer trayecto, entre Barcelona y Granollers, en 1969. Acesa fue la concesionaria del tramo entre La Junquera y Tarragona y Aumar entre Tarragona y Alicante. La autopista del Ebro (AP-68), con una longitud de 295 kilómetros, fue construida entre 1975 y 1980 por Avasa (Autopista Vasco-Aragonesa). Por último, la autopista del Nordeste (AP-2), con 220 kilómetros, unía Zaragoza con Barcelona y Tarragona, enlazando con la AP-7. Se construyó entre 1974 y 1979, y su concesionaria también fue Acesa.

31. El proyecto de los tramos de peaje de la autopista del Noroeste (AP-6) se aprobó en 1967, quedando finalizados en 1977; por su parte, el tramo de la autopista del Norte (AP-1) entre Burgos y Armiñón (84,3 kilómetros) se adjudicó en 1974 a Europistas y entró en servicio en 1984. La AP-8 se construyó también por Europistas en la década de los setenta, como primera fase de la autopista/autovía del Cantábrico, con una longitud de 116 kilómetros.

32. Además surgieron importantes problemas para la Hacienda, derivados de la inclusión en las concesiones de autopistas de cláusulas mercantiles, fiscales y financieras para favorecer a los concesionarios, que finalmente fueron recogidas en la Ley 8/1972, de construcción, conservación y explotación de autopistas en régimen de concesión. En virtud de dichas cláusulas, el Estado se comprometía a facilitar a los concesionarios las divisas para el pago del servicio de la deuda y el mismo tipo de cambio de compra vigente el día de constitución del préstamo. Posteriormente, el seguro de cambio fue derogado para las nuevas concesiones en la Ley de carreteras de 1988. Hasta finales de 1996 el coste del seguro de cambio que el Estado tuvo que pagar fue de 2.885,7 millones de euros, cifra que equivalía a más de 4 euros por cada euro que había sido efectivamente desembolsado por los inversores privados (Fernández, Molina, Nebot, 1983:48; Bel, 1999:132). 
Además de las actuaciones citadas, en virtud del Programa de redes arteriales de las grandes poblaciones se construyeron 241,4 kilómetros de autopistas libres de peaje, en su mayor parte urbanas o suburbanas. También se realizaron 135, 6 kilómetros de autovías, siendo la más importante la de Santa María del Mar-Los Cristianos, de 66,7 kilómetros en Tenerife, ligada al sector turístico.

En su conjunto, las actuaciones referidas permitieron en gran parte acomodar la oferta de infraestructuras de carreteras a los incrementos de los tráficos que se habían producido desde los años sesenta en España y conllevaron un notable incremento de las inversiones públicas dedicadas a este fin, como puede apreciarse en el gráfico 3. Las cantidades presupuestadas para inversiones se multiplicaron hasta mediados de los setenta, mientras que los recursos destinados a conservación y reparación crecieron en menor medida en esos mismos años.

Gráfico 3. Evolución de las inversiones en carreteras en España, 1900-1985. (En millones de pesetas de 1913)

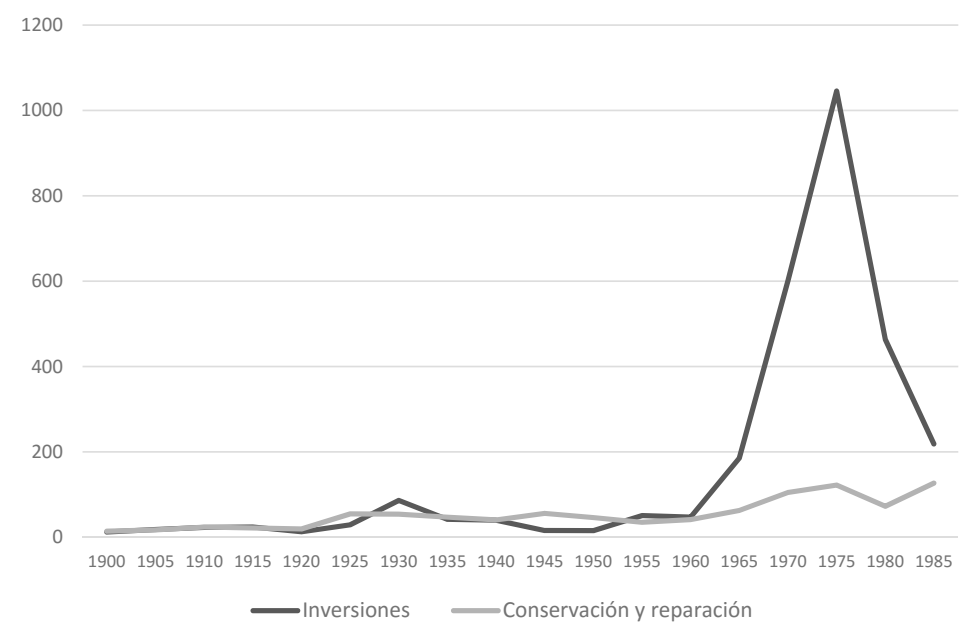

Fuente: Uriol (1992: 182-185). Elaboración propia.

LA DESCENTRALIZACIÓN ADMINISTRATIVA DE LA RED ESTATAL Y EL PREDOMINIO EN ESPAÑA DE LAS VÍAS DE GRAN CAPACIDAD SIN PEAJE

El proceso de transformación institucional y económico vivido por España tras la restauración de la democracia trajo consigo, entre otras cosas, una descentralización del sector público. Durante la Transición dicho proceso, diseñado en la Constitución de 1978, supuso la mutación desde un Estado fuertemente centralizado a un Estado cuasi federal. La nueva configuración político-administrativa 
quedó reflejada en la participación de los diferentes niveles de gobierno en el gasto público. En 1980 la administración central absorbía el 90\% del gasto público no financiero, correspondiendo el $10 \%$ restante a las corporaciones locales; nueve años después, la participación de las comunidades autónomas ascendía al $21 \%$ y la de las corporaciones locales al 13\%, lo que rebajaba el gasto de la administración central a un $66 \%$. Y esta tendencia no hizo nada más que incrementarse en los años siguientes a favor de los nuevos órganos de gobierno.

En lo que respecta a las carreteras, el período que se abre a partir de 1978 se caracterizó por la transferencia por el Estado central de una parte de la red a las comunidades autónomas (CCAA), por la brusca caída de las inversiones y por la disminución de los parques y tráficos por carretera, lo que guardó estrecha relación con las sucesivas crisis energéticas, especialmente las del petróleo. Por lo que se refiere al primero de los aspectos, el capítulo VIII de la Constitución de 1978 contemplaba que las carreteras que discurrieran en su totalidad por una comunidad autónoma debían ser gestionadas por ella; es decir, que todas las carreteras no nacionales debían segregarse de la red de interés general del Estado y transferirse a las CCAA. Este proceso de transferencia de competencias se desarrolló entre 1980 y 1984, de manera que en 1985 la Red de Interés General del Estado (RIGE) quedó reducida a 20.322 kilómetros, que en 1997 ascendieron a $23.397^{33}$. A medida que se producía el adelgazamiento de la red de titularidad estatal, se incrementaba en paralelo el volumen que pasaba a ser competencia de las entidades autonómicas, al que se sumó también, en el caso de las CCAA uniprovinciales, las carreteras de las diputaciones provinciales y las de los cabildos en el de las islas. Las inversiones del Estado en la red central experimentaron una brusca caída en consonancia con su menor tamaño, pasando desde los 743 millones de pesetas en 1978 a los 218 de 1985; lo que no fue óbice para que en la RIGE se concentrara más del $60 \%$ del tráfico total por carretera.

El Plan General de Carreteras de la RIGE de 1984-1991 sustituyó al de 1961. El Congreso de los Diputados recomendó al Gobierno que tomara las medidas oportunas en las leyes de Presupuestos Generales para asegurar la financiación del Plan General de Carreteras (PGC), por considerarlo absolutamente necesario para alcanzar la adecuada calidad de vida de los ciudadanos, el desarrollo y el equilibrio territorial del país. El Plan se estructuró en cuatro programas, que debían estar concluidos antes de 1992: 1) Programa de

33. Téngase en cuenta, al respecto, que en 1979 la RIGE contaba con 81.130 kilómetros (Lazcano, Uriol, Lacleta, 1999:152). Por su parte, del total de la red que seguía siendo competencia estatal en 1997, 1.752 eran autopistas de peaje; 5.167 vías de alta capacidad incluyendo autopistas libres y autovías; y el resto, 16.478 kilómetros de carreteras convencionales. 
autovías, que preveía 2.359 kilómetros en itinerarios completos ${ }^{34}$; 2) Programa de acondicionamiento de la red (ARCE) con 7.000 kilómetros de carreteras de dos carriles, acondicionamientos locales y la realización de 200 variantes en núcleos de menos de 50.000 habitantes; 3) Programa de reposición y conservación (RECO), que incluía la pavimentación periódica de los itinerarios, tratamiento de intersecciones y supresión de más de 80 pasos a nivel; y 4) Programa de actuaciones en medio urbano (ACTUR), cuyo objetivo era mejorar los accesos a poblaciones importantes, así como a puertos y aeropuertos de interés general. En 1986 se revisó el Plan ampliando el programa de autovías a 3.538 kilómetros. Como puede verse en el cuadro 1, el PGC preveía un programa de actuación que afectaba a más del $90 \%$ de la superficie de la red estatal, quedando tan sólo fuera las autopistas de concesión estatal de las comunidades forales de Navarra y País Vasco. Para ello, se estimaba una inversión de 809 mil millones de pesetas. Una previsión que se vio ampliamente superada debido a la inflación y al aumento de los costes de construcción motivado por la mejora de las características de las vías y por las ampliaciones. En 1989 el importe total del Plan se cifró en 1,5 billones de pesetas, más del $85 \%$ del valor inicialmente presupuestado. Las comunidades a las que el PGC destinaba un mayor presupuesto eran las que tenían una mayor extensión territorial y una red viaria estatal con más kilómetros. Encabezaban el listado Castilla-León, Andalucía y Castilla-La Mancha; y le seguían la Comunidad Valenciana, Galicia, Cataluña, Aragón y Madrid; figurando en último lugar La Rioja. El coste por kilómetro más elevado recaía en Madrid, siendo más del doble de la media. También era superior a la media el coste en Murcia, Cantabria, la Comunidad Valenciana, Cataluña y Andalucía; mientras que por debajo se situaba en La Rioja, Aragón, Castilla-León, Extremadura, Galicia, Castilla-La Mancha y Asturias, está última estaba prácticamente en la media que era de 43.958,55 pesetas el kilómetro.

34. La Ley de Carreteras definía las autovías como «carreteras que no reuniendo todos los requisitos de las autopistas estén concebidas, construidas y señalizadas para la exclusiva circulación de automóviles y no tengan acceso a ellas las propiedades circundantes». La diferencia estribaba en que en estas vías de inferior categoría se toleraban las intersecciones a nivel con otras carreteras y no se exigía obligatoriamente la separación de calzadas de distinto sentido por fajas de terreno o barreras (Llamazares, 1983:822). 
Cuadro 1. Programa de actuación y presupuesto de inversión estimado por el Plan General de Carreteras de la RIGE, 1984-1991

\begin{tabular}{|c|c|c|c|c|c|c|}
\hline \multirow[b]{2}{*}{ Comunidad } & \multicolumn{2}{|c|}{ RIGE (1) } & \multicolumn{2}{|c|}{ Programa de Actuación } & \multicolumn{2}{|c|}{ Presupuesto } \\
\hline & $\mathbf{K m}$ & $\%$ & $\mathbf{K m}$ & $\%$ & $\begin{array}{l}\text { Millones } \\
\text { Ptas }\end{array}$ & $\%$ \\
\hline Andalucía & $2.651,4$ & 13,0 & $2.565,8$ & 13,9 & 127.000 & 15,7 \\
\hline Aragón & $2.040,6$ & 10,0 & $1.878,0$ & 10,2 & 58.000 & 7,2 \\
\hline Asturias & 624,6 & 3,1 & 604,5 & 3,2 & 26.000 & 3,2 \\
\hline Cantabria & 387,4 & 1,9 & 387,4 & 2,1 & 26.000 & 3,2 \\
\hline Castilla-La Mancha & $2.912,7$ & 14,3 & $2.908,3$ & 15,8 & 115.000 & 14,2 \\
\hline Castilla y León & $4.115,4$ & 20,3 & $3.888,9$ & 21,1 & 137.000 & 16,9 \\
\hline Cataluña & $1.736,7$ & 8,6 & $1.153,2$ & 6,2 & 59.000 & 7,3 \\
\hline Comunidad Valenciana & $1.532,8$ & 7,6 & $1.284,6$ & 6,9 & 82.000 & 10,1 \\
\hline Extremadura & $1.194,0$ & 5,9 & $1.194,0$ & 6,4 & 46.000 & 5,7 \\
\hline Galicia & $1.596,9$ & 7,9 & $1.505,5$ & 8,1 & $58.000(2)$ & 7,2 \\
\hline La Rioja & 394,9 & 1,9 & 276,4 & 1,5 & 5.000 & 0,6 \\
\hline Madrid & 454,0 & 2,2 & 439,5 & 2,3 & 45.000 & 5,6 \\
\hline Murcia & 353,6 & 1,7 & 353,6 & 1,9 & 25.000 & 3,1 \\
\hline Navarra (3) & 140,2 & 0,7 & - & - & - & - \\
\hline País Vasco (3) & 187,5 & 0,9 & - & - & - & - \\
\hline ESPAÑA & $20.322,7$ & 100,0 & $18.403,7$ & 100,0 & 809.000 & 100,0 \\
\hline
\end{tabular}

(1) Incluye autopistas de peaje.

(2) Habría que sumar 18.000 millones de pesetas de la autopista Santiago-Pontevedra, a la que el MOPU aportaba 7.500 millones de pesetas.

(3) Incluye únicamente las autopistas de concesión estatal.

Fuente: Plan General de Carreteras 1984-1991. Elaboración propia.

E1 Plan General de Carreteras 1984-1991 fue un paso importante en el camino hacia la equiparación de las infraestructuras españolas con las europeas. Aunque resulta evidente que este Plan no resolvió por sí solo todos los problemas acuciantes que pesaban sobre la red principal, si que puede afirmarse que representó un salto hacia delante en la mejora de la calidad de las carreteras españolas y contribuyó decisivamente a equiparar las comunicaciones con las de los países más desarrollados de nuestro entorno. En este proceso de mejora tuvo mucho que ver la red de autovías que se construyó con los presupuestos públicos. Aunque, en términos generales, resulta innegable que la calidad del servicio prestado por la autopista es superior al que pueda prestar la autovía, el empleo de la autovía como vía rápida en la red contemplada por el PGC resultó providencial. La limitación de los recursos financieros que se podían dedicar a la construcción de estas infraestructuras y la mayor economía de la autovía aconsejaron su uso 
con la finalidad de lograr mejoras rápidas de calidad. Además, con la autovía se atendía al tráfico local, que era el preponderante, de forma mucho más satisfactoria que con la autopista. De esta manera, las vías de alta intensidad, que anteriormente bajo la técnica de autopistas se habían concedido a empresas privadas, se incluyeron ahora en los presupuestos del Estado con una solución técnica más barata, la autovía, que se obtenía desdoblando la carretera existente. En 1993 España contaba con 3.431 kilómetros de autovías, casi 200 más de los previstos inicialmente, y en 1997 la cifra ascendía a 5.167 kilómetros. La aplicación del PGC modificó de forma sustancial la fisonomía de la red estatal, ya que conllevó un considerable incremento de las vías de alta capacidad y, en particular de las autovías ${ }^{35}$.

Según Bel (2011:153), los recursos empleados en el PGC fueron muy superiores a los previstos inicialmente, y ello se debió sobre todo a la gran inversión en autovías: 7.500 millones de euros, que consumieron casi la mitad de los recursos totales del Plan. Las nuevas carreteras supusieron también un considerable avance en los estándares de calidad tanto en los requerimientos de trazado como en lo referido a otras características, de tal modo que las más recientes se asemejaron mucho a las autopistas. Los cambios de criterio estuvieron en cierto modo influidos por el ingreso de España en la Comunidad Europea y fueron un factor decisivo en el alza de los presupuestos del Plan. En términos generales, puede decirse que el PGC tuvo como objetivo básico la mejora del tráfico en la red de carreteras españolas, pero esta finalidad se acompañó con otras motivaciones, más de carácter político, como fue facilitar la conexión con Portugal y con las demás rutas europeas, y sobre todo llevar a cabo un reequilibrio territorial entre las diferentes regiones españolas. En opinión de Bel (2011:158), sin embargo, los criterios del PGC de 1984-1991 respondieron más a motivaciones de centralización que a criterios de solidaridad interterritorial. Las cuatro comunidades autónomas en las que más kilómetros de autovía se construyeron fueron Castilla-La Mancha, Castilla-León, Andalucía y Comunidad Valenciana. Todas ellas eran Objetivo I de la Comunidad Europea, lo que permitió obtener cofinanciación de la política regional comunitaria, mediante los fondos FEDER.

Por su parte, el Plan Director de Infraestructuras (PDI) de 1993-2007, elaborado por el Ministerio de Obras Públicas, Transportes y Medio Ambiente (MOPTMA), fue el documento básico de planificación que sirvió de marco de

35. Así, los 724,6 kilómetros de vías de alta capacidad (que incluían autopistas libres y autovías) existentes en 1985 ascendieron en 1997 a 5.167 kilómetros, lo que equivalía a pasar del $3,57 \%$ del total de la red a más del 22\%; mientras que los kilómetros de autopistas de peaje prácticamente no se modificaron (pasando de 1.797 en 1985 a 1.752 en 1997) y las carreteras convencionales acortaron su trazado de 17.800 kilómetros a 16.478 , rebajando su porcentaje del $88 \%$ al $70 \%$. Esto último se debió a que, en muchos casos, las vías de alta densidad aprovecharon el trazado ya existente. 
referencia para el desarrollo de la mayor parte de infraestructuras de competencia estatal en dicho período. El PDI englobaba distintos planes nacionales, entre ellos el de carreteras. Durante su período de ejecución se pretendía invertir 18,7 billones de pesetas (pesetas constantes de 1992), lo que significaba 1,2 billones de pesetas por año. Esta inversión se sustentaba en unas previsiones hasta 2007 de crecimiento medio del PIB del 2,5\% anual. Del total presupuestado, 10,7 billones se destinarían a infraestructuras de transporte interurbano y, de esta cantidad, 5,4 billones debían dedicarse a carreteras, siendo el 95\% capital público y el resto privado, especialmente vía autopistas de peaje.

Como se ha indicado, las autopistas fueron sustituidas en los planes del Estado por autovías de régimen libre financiadas directamente por los presupuestos generales ${ }^{36}$. El Gobierno socialista surgido de las urnas en 1982 creó, en 1984, la Empresa Nacional de Autopistas (ENAUSA), que absorbió diversas concesiones de autopistas que habían resultado fallidas y se habían mostrado incapaces para ejecutar los tramos adjudicados. Era el caso de Ferrol-Tuy (Autopistas del Atlántico, Audasa); Tudela-Irurzun (Autopistas de Navarra, Audenasa); y Campomanes-León (Astur-Leonesa, Aucalsa) ${ }^{37}$. Sin embargo, un nuevo rumbo se produjo con el Gobierno del Partido Popular (PP) a partir de 1996, al plantear éste una política de carreteras más favorable al peaje a través de dos programas: 1) prolongación de las concesiones de autopistas y 2) el Programa de Autopistas de Peaje de 1997. La red de autopistas de peaje de titularidad estatal que tenía 1.752 kilómetros en 1997 pasó a tener 2.493 en 2008, ascendiendo el total de la red de autopistas de titularidad del Estado a 10.126 kilómetros $^{38}$.

36. Los kilómetros de autopista incluso se redujeron en este periodo (1.797 kilómetros en 1985 frente a 1.752 en 1997) frente al notable crecimiento que experimentaron en esas mismas fechas los de autovía.

37. Con la autopista del Atlántico (AP-9) se trataba de comunicar de norte a sur el oeste de Galicia, desde Ferrol a la frontera con Portugal. Su construcción fue concedida en 1973 a Audasa, hoy del grupo Itínere, perteneciente a Sacyr Vallehermoso. La autopista de Navarra (AP-15), con una longitud de 112,15 kilómetros, vertebra esta comunidad de norte a sur. En 1973 se constituyó la sociedad para su construcción y en enero de 1976 se inauguró el primer tramo, entre Noáin y Tafalla. La autopista completa se abrió en 1980. La sociedad concesionaria es Audenasa, que está participada en un $50 \%$ por el grupo Itínere y en otro $50 \%$ por el Gobierno de Navarra. En 2029 está prevista la reversión al Gobierno Foral. Por último, la AP-66 es un tramo de peaje que forma parte de la Ruta de la Plata, vía de alta capacidad con la que se pretende unir, una vez esté completada, Gijón y Sevilla. La AP-66 une Asturias y León, y tiene una longitud de 78 kilómetros. Se inició su construcción en 1975 y en 1983 se abrió al tráfico su primera fase, terminándose en su totalidad en 1997, con el desdoblamiento del túnel del Negrón. Su concesionaria también pertenece a la sociedad empresarial Itínere.

38. Del total, 7.633 kilómetros eran libres de peaje, lo que equivalía al $75 \%$ de la red y el $25 \%$ restante era de peaje. 
Gráfico 4. Evolución de la red de autopistas del Estado, 1972-2008

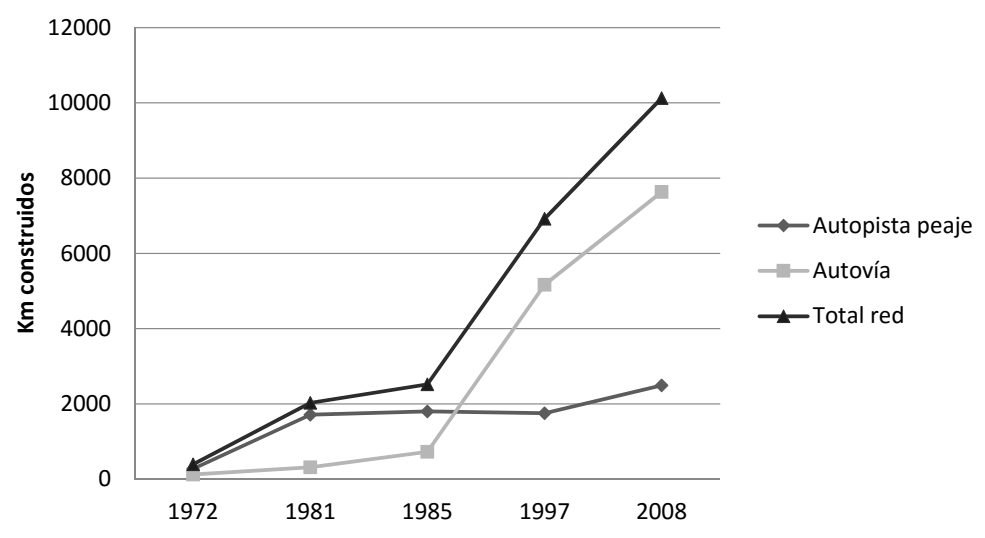

Fuente: Ministerio de Fomento, Anuarios Estadísticos. Elaboración propia.

La evolución de red de autopistas del Estado puede verse en el gráfico 4, en el que queda evidenciado cómo a partir de mediados de los ochenta se invirtió la tendencia en favor de la fórmula autovía. Así, las autovías y autopistas libres de peaje pasaron de ser el 15,6\% del total de la red de titularidad pública en 1981 al $75,4 \%$ en 2008 , mientras que se invertía en igual proporción la participación de las autopistas de peaje, que de ser el $84,4 \%$ de la red estatal se ha reducido hasta menos del 25\%. La fecha del ingreso de España en la Comunidad Europea marcó un punto de inflexión muy significativo en cuanto al crecimiento de los kilómetros de la red, que casi se quintuplicó entre 1985 y 2008, y también en lo referente al cambio de modelo constructivo y de explotación, en detrimento de las autopistas de peaje. Este nuevo enfoque tuvo que ver con las posibilidades financieras que los organismos europeos brindaron al país para la construcción de infraestructuras a través de sus fondos. El resultado de todo ello ha sido que en España se ha implantado un modelo mixto, que conlleva la cohabitación de diferentes formas de financiación -presupuesto público y peajes- de la inversión y del mantenimiento de la red de autopistas del Estado. Este modelo mixto de financiación, muy singular en el marco de la UE, ha generado además, dada la gran variabilidad interterritorial del peso de los peajes, una asimetría que provoca desigualdades entre ciudadanos y empresas en función del lugar en el que están radicadas las infraestructuras ${ }^{39}$.

En cuanto a la titularidad de las vías, como puede apreciarse en el gráfico 5, la red de carreteras de España tenía a finales de 2010 una extensión de 165.787

39. Respecto a la peculiaridad del sistema mixto español de financiación de autopistas entre los países de la UE, puede verse Albalate, Bel y Fageda (2009). 
kilómetros, de los cuales 25.733 (RCE) estaban gestionados por la administración central, lo que significaba poco más del $15 \%$ del total, que absorbía, sin embargo, más del $50 \%$ del tráfico total y más del $62 \%$ del tráfico pesado. Las carreteras dependientes de la administración central se han reducido desde los años ochenta como consecuencia del proceso de descentralización que el país ha vivido con la creación del Estado de las Autonomías; de manera que parte de la red estatal ha pasado a ser titularidad de las comunidades autónomas. Así, con datos de 2010, poco más del $15 \%$ de la red era de competencia estatal, mientras que las CCAA gestionaban más del 43\% (71.464 kilómetros), que absorbían un porcentaje similar del tráfico; correspondiendo el resto, 68.590 kilómetros $(41,4 \%)$, a la gestión de diputaciones y cabildos, que, por el contrario, tenían poco tráfico $(5,8 \%)$. Además, los ayuntamientos tenían a su cargo 489.698 kilómetros, de los cuales 361.517 eran de carácter interurbano. Por su tipología, la administración central tiene a su cargo el mayor número de kilómetros de autopistas y autovías. En el caso de las primeras, la práctica totalidad; mientras que de las segundas gestionaba, en 2010 , más del $72 \%$ de la red. Las comunidades autónomas, por su parte, eran las responsables de administrar la casi totalidad del resto de redes de alta densidad y la mitad de la red convencional; mientras que diputaciones y cabildos gestionaban, en su mayoría, carreteras convencionales (en más de un 98\%).

Gráfico 5. Evolución de la red de carreteras españolas por titularidad administrativa, 1970-2010

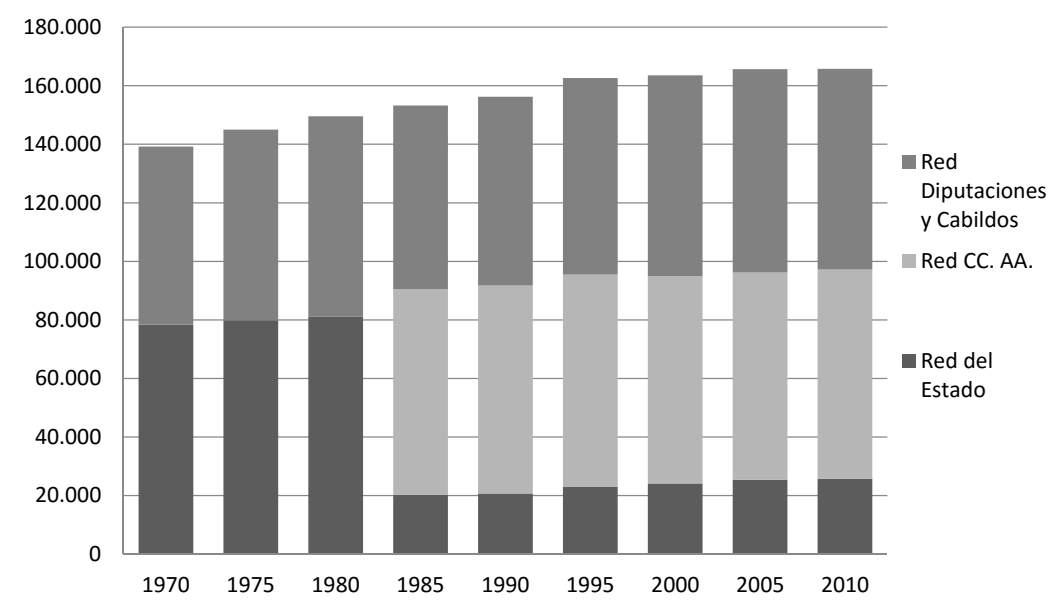

Fuente: Ministerio de Fomento, Anuario Estadístico, 2013. Elaboración propia 
Gráfico 6. Evolución de la red de carreteras españolas por su tipología,

1970-2010

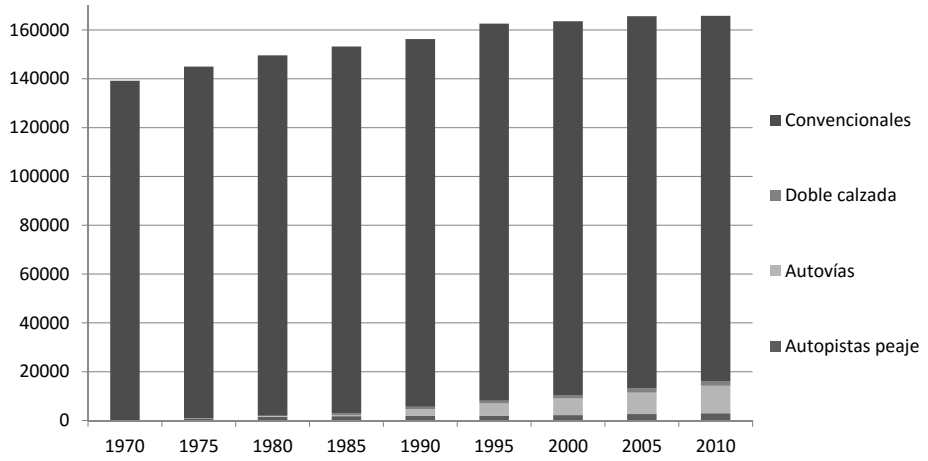

Fuente: Ministerio de Fomento, Anuarios Estadísticos. Elaboración propia

En síntesis, el crecimiento del total de la red de carreteras españolas entre 1970 y 2010 fue de un 19\%, correspondiéndole el mayor aumento a las vías de gran capacidad, como puede verse en el gráfico 6. Las carreteras convencionales incluso decrecieron a partir de los años noventa, a medida que se incrementaban los kilómetros de la red de gran capacidad, sobre todo las autovías. De la totalidad de la red, 15.965 kilómetros eran en 2010 vías de gran capacidad (autopistas de peaje, libres, autovías y carreteras de doble calzada), lo que ha llevado a España a ser en la actualidad el país de Europa con mayor longitud de este tipo de vías. El segundo es Alemania con 12.879 kilómetros y Francia el tercero con 11.465, según datos de la agencia europea EUROSTAT, para 2012. El crecimiento de las vías de gran capacidad fue espectacular en el período estudiado, casi se multiplicaron por 80 los kilómetros existentes entre $1970 \mathrm{y}$ 2010, correspondiendo el mayor aumento a las autovías. Así, más del 70\% de las vías de gran capacidad existentes en España en 2010 eran de este tipo, habiéndose multiplicado su longitud con respecto a 1970 casi por 100. El momento de mayor desarrollo fue a partir de mediados de los años ochenta, en que la red de autovías creció a un ritmo de unos 2.000 kilómetros por quinquenio. Las autopistas de peaje se incrementaron en menor medida, si bien también experimentaron un fuerte desarrollo, ya que entre 1970 y 2010 los kilómetros de autopista se multiplicaron casi por treinta. Así, se pasó de 82 en 1970 a casi 3.000 en 2010. Las series de stock de capital elaboradas por el IVIE para el período 1955-2002 ponen de manifiesto asimismo el notable esfuerzo inversor desarrollado en la creación de infraestructuras de transporte en las últimas décadas del siglo xx (Mas et al.:2007). Concretamente, se destacan dos períodos de fuerte inversión: 1963-1977, cuando se alcanzan tasas de incremento del stock entorno 
al $10 \%$ anual, lo que coincide con la construcción de la mayor parte de la red de autopistas privadas de peaje del país; y 1988-1995, que se corresponde con la puesta en marcha de la política de construcción de autovías de libre acceso (Nombela: 2005:194). Este trabajo evidencia también que, durante la segunda mitad de los años cincuenta, la red de carreteras prácticamente no tuvo cambios, y lo mismo puede decirse del período de crisis 1978-1986, en que la inversión para aumentar el stock de carreteras fue mínima.

\section{CONCLUSIONES}

La necesidad de dar respuesta al freno que suponía la deficitaria red de transporte terrestre para el crecimiento de la economía española se convirtió en un objetivo básico de la política inversora del Estado durante todo el siglo xx. La aparición y desarrollo de la industria automovilística y el aumento del tráfico de viajeros y mercancías por carretera exigieron incrementar la extensión y mejorar la calidad de la red viaria española. Varias etapas pueden señalarse en este empeño. En cuanto a la longitud de la red, un primer esfuerzo constructor puede situarse en el primer tercio del siglo xx, desempeñando un papel importante, en este sentido, el Circuito Nacional de Firmes Especiales (1926), con el que se puede decir se inició la etapa contemporánea del transporte por carretera en España. Tras el parón constructivo que supuso la larga postguerra civil, durante la cual sólo merece destacarse el Plan de Modernización de la Red de Carreteras de los años cincuenta, un nuevo impulso tuvo lugar a partir de 1960, en que se multiplicaron las inversiones públicas destinadas a este fin. La correlación con el incremento que se produjo en este mismo período del número de automóviles existente en España es manifiesta. Fueron los años del boom automovilístico y del auge de la fabricación de vehículos en España. Esta etapa, marcada por el Programa REDIA (1967), finalizó con la crisis de mediados de los setenta. Los cambios institucionales y económicos que acompañaron a la transición democrática tuvieron un notable protagonismo sobre la red viaria española. Asistimos, durante esos años, a una brusca caída de las inversiones que llevó aparejado un estancamiento de la longitud de la red y a la transferencia de una parte significativa de las carreteras a las nacientes Comunidades Autónomas.

El Plan General de Carreteras de 1984-1991 marcó un nuevo hito en la historia de la modernización de la red viaria española. El país realizó, como se ha visto, desde mediados de los años 80 y ayudado por los fondos europeos, un esfuerzo considerable para superar sus carencias en infraestructuras de transporte. Desde finales de los ochenta y hasta mediados de los noventa del siglo xx, ocupó, junto con Alemania, el primer puesto en la Unión Europea en cuanto al porcentaje del PIB dedicado a la inversión en infraestructuras de transporte. Desde el umbral del 0,5-0,6\% del PIB de la primera fecha se ha 
llegado a valores en torno al 1,7-1,8\% del PIB en las más recientes; si bien pueden apreciarse fuertes variaciones que están estrechamente vinculadas al ciclo económico. Esta «vorágine inversora», en palabras de Bel (2010:212), se prolongó hasta la eclosión de la crisis económica a partir de 2008, favorecida por la afluencia de recursos de que gozaron las administraciones públicas españolas y por la existencia de una creencia casi incuestionable de que cualquier inversión en infraestructuras era buena por sí misma. En 2004 podría afirmarse que, en gran medida, se había corregido la vieja red radial iniciada en el siglo XVIII y que España caminaba hacia una red mallada, formada por autopistas, autovías y carreteras convencionales.

En definitiva, el crecimiento económico, las transformaciones sociales, los cambios producidos en la configuración territorial del país y la hegemonía de la cultura pro-inversión en infraestructuras han ejercido una presión constante sobre las administraciones públicas en demanda de un permanente incremento y mejora de la calidad de los servicios y de las infraestructuras de transporte terrestre. El resultado de estas décadas de elevadas inversiones ha sido que España ha pasado de ser un país inmaduro en materia de infraestructuras a contar con una red madura, que le ha hecho converger con Europa en términos de equipamiento en grandes infraestructuras de transporte, y muy en particular en autovías y autopistas. El resultado de todo ello ha sido el desarrollo de una red de comunicaciones moderna y eficiente que ha contribuido al crecimiento económico del país.

\section{BIBLIOGRAFÍA}

Aguilar, M. (1925): «La circulación automóvil, el régimen fiscal y la mejora de las carreteras», ROP.

Albalate, D.; Bel, G. y Fageda, X. (2009): «Privatization and regulatory reform of toll motorways in Europe», Governance, 22 (2).

Álvarez Junco, J. (2001): Mater Dolorosa. La idea de España en el siglo XIX. Taurus, Madrid.

Álvarez, A., Orea, L. y FernÁndeZ, J. (2003): «La productividad de las infraestructuras en España», Papeles de Economía Española, 95.

Alzola, P. (1979): Historia de las obras públicas en España. Turner, Madrid.

Argimón, I., González-Páramo, J.M., Martín, M.J. y Roldán, J.M. (1994): «Productividad e infraestructuras en la economía española», Moneda y Crédito, 198.

Ashauer, D.A. (1989): «Does public capital crowd out private capital?», Journal of Monetary Economics, 24.

Ashauer, D.A. (1993): «Public capital, productivity and economic growth». Infrastructure and Competitiveness, John Deutsch Institute for the Study of Economic Policy, Ontario. 
Barciela, C., López, M. I., Melgarejo, J. y Miranda, J. A. (2001): La España de Franco. Economía, 1939-1975. Síntesis. Madrid.

Banco Mundial (1962): El desarrollo económico de España. Madrid.

BEL, G. (1999): «Financiación de infraestructuras viarias: la economía política de los peajes», Papeles de Economía Española, 82.

BEL, G. (2010): «La racionalización de las infraestructuras de transporte en España», Cuadernos Económicos de ICE, 80.

BeL, G. (2011): Espanya, capital París. La Campana. Barcelona.

BIEHL, D. (1986): «The contribution of infrastructure to regional development», Report on the Infrastructure Studies Group to the European Commission, Luxemburgo.

BIEHL, D. (1988): «Las infraestructuras y el desarrollo regional», Papeles de Economía Española, 35.

Catalan, J. (2011): «La Seat del Ibiza, 1981-2010: fuerza de una marca resistencia de un distrito», en Catalan, J.; Miranda, J. A. y Ramón-Muñoz (eds.): Distritos y Cluster en la Europa del Sur. LID, Madrid.

De la Fuente, A. (1996): «Infraestructuras y productividad: un panorama de la evidencia empírica», Información Comercial Española, 757.

Draper, M. y HerCe, J.A. (1994): «Infraestructuras y crecimiento: un panorama», Revista de Economía Aplicada, 6.

Fernández, R., Molina, E. Nebot, F. (1983): «El fracaso de la política de las autopistas de peaje», ICE, 594.

FERnÁNDEZ DE SEVILla, T. (2011): «Los orígenes del cluster del automóvil de Valladolid: el papel de Fasa como empresa líder, 1951-1965», en Catalan, J.; Miranda, J. A. y RAMón-MuÑoz (eds.): Distritos y Cluster en la Europa del Sur. LID, Madrid.

FORD, R. (1974): Las cosas de España. Turner, Madrid.

GARCÍA OrmaecheA, P. (1957): «La red de carreteras españolas. Su modernización», ROP.

GARCÍA ORTEGA, P. (1979): Las concesiones administrativas de carreteras en el ordenamiento jurídico español. MOPU, Madrid.

Gómez Mendoza, A. (2001): «Madrid, centro de la red de comunicación». Arbor, 169. GRUPO ESM (1995): Las carreteras españolas y sus pavimentos en el siglo XX. Madrid.

Herranz Locán, A. (2004): La dotación de infraestructuras en España (1884-1935). Estudio 45. Banco de España.

Hirschman, A. (1958): The Strategy of Economic Development, New Haven/London.

LlamaZARES Gómez, O. (1983): «Sobre el desarrollo de la infraestructura viaria y sus soluciones futuras. $R O P$.

Madrazo, S. (1984). El sistema de comunicaciones en España, 1750-1850, Turner, Madrid.

Lazcano, J. F., Uriol, J. I. Lacleta, A. (1999): «Carreteras», ROP, 3.388.

MAs, M., PÉrez, F., URIol, E. (2007): El stock de capital y los servicios de capital en España y su distribución territorial (1964-2005). Nueva metodología. BBVA.

Marín Quemada, J.M. (1979): «Política petrolífera de la Dictadura», Cuadernos Económicos de ICE, 10. 
Ministerio de Transportes y COMUniCACiOnes (1979): Estadísticas de Transportes. Series Cronológicas (1950-1977). Instituto de Estudios de Transporte y Comunicaciones.

Ministerio de Obras Públicas (1940): Plan General de Obras Públicas.

Mopu (1986): Plan General de Carreteras 1984/91. Redacción actualizada mayo 1986.

Mopt (Ministerio de Obras Públicas y Transporte) (1993): Plan Director de Infraestructuras 1993-2007.

Ministerio de Fomento (2004): Plan Estratégico de Infraestructuras y Transporte (PEIT). Madrid.

Ministerio DE Fomento (2009): Los transportes, las infraestructuras y los servicios postales. Informe Anual 2008. Madrid.

Ministerio de Fomento (2013): Anuario Estadístico 2012. Madrid.

Nombela, G. (2005): «Infraestructuras de transporte y productividad», Presupuesto y Gasto Público, 39.

Peña Boeuf, A. (1946): «Desarrollo de las obras públicas en España», ROP.

Revista de Obras Públicas (1939): Resumen de las destrucciones de la guerra en la Red de Caminos del Estado, número extraordinario dedicado a la Cruzada Española. 1936-1939,

RodríGuez LÁzARo, F. J. (2004): Las primeras autopistas españolas (1925/1936), Colegio de Ingenieros de Caminos, Canales y Puertos, Madrid.

Rodríguez SAIZ, L. (1979):»La política de transportes en la Dictadura de Primo de Rivera», Cuadernos Económicos ICE, 10.

SAN Román, E. (1995): «El nacimiento de la SEAT: autarquía e intervención del INI». Revista de Historia Industrial, 7.

SAn Román, E. (2010): «Política económica y atraso automovilístico (1900-1936): el caso español en perspectiva comparada con Japón», Revista de Historia Industrial, 46.

SEgurA, C. (2000): «Madrid, capital imperial 1561-1883», en Santos Julia, David Ringrose y Cristina Segura: Madrid. Historia de una capital. Alianza Editorial, Madrid.

Tinbergen, J. (1962): Shaping the World Economy. Nueva York.

Tortella, G.; Ballestero, A. y Díaz Fernández, J. L. (2003): Del monopolio al libre mercado. La historia de la industria petrolera española. LID, Madrid.

URIOL SALCEDO, J. I. (1977): «Los viajes por la posta en el siglo XVIII y en los primeros años del siglo XIX», ROP, 3.151.

Uriol Salcedo, J. I. (1990): Historia de los caminos de España. Ed. AC, Madrid.

Uriol Salcedo, J. I. (1992): Historia de los caminos de España, Colegio de Ingenieros de Caminos, Canales y Puertos, Madrid. 